\title{
Efficiency and acceptance of new water allocation rules - the case
} of an agricultural water users association

\author{
Renan U. Goetz ${ }^{\mathrm{a}}$, Yolanda Martínez ${ }^{\mathrm{b}}$, Àngels Xabadia ${ }^{\mathrm{a}^{*}}$ \\ aDepartment of Economics, University of Girona, Carrer de la Universitat de Girona 10, 17003 Girona, \\ Spain \\ ${ }^{b}$ Department of Economic Analysis, Institute of Agrifood Research and Technology (IA2), University of \\ Zaragoza-CITA, Gran Vía, 2, 50005 Zaragoza \\ *Corresponding author. angels.xabadia@udg.edu. Senior authorship is shared by Yolanda Martinez and \\ Angels Xabadia.
}

\begin{abstract}
Water scarcity is one of the major environmental problems in Southern Europe. High levels of water stress and increasing frequency of droughts, along with a greater environmental protection, make it necessary to design water management strategies that are allocative efficient and balance supply and demand. When functioning markets cannot be developed, the allocation rules proposed in the literature of social choice have been recognized as a suitable alternative. However, the application of new water allocation rules can be impaired by a lack of acceptance and implementation problems. This paper examines these obstacles for the case of an agricultural water user association (WUA), situated in the basin of the river Ebro, in relation with the governance structure and collective decision rule of the WUA. It analyzes the extent to which the gains and losses of the farmers affect their acceptance, and examines conditions for building agreements with side payments that provide incentives for the majority of the farmers to form part of a possible agreement. The results show that the uniform and sequential rules improve the allocative efficiency under normal conditions compared to the status quo and the sequential rule even in the case of droughts. In the presence of side payments this rule is likely to be accepted and has only an insignificant impact of distributional inequality.
\end{abstract}

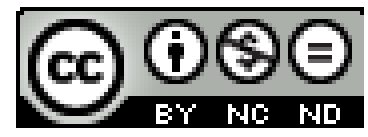

(C) <2017>. This manuscript version is made available under the CC-BY-NC-ND 4.0

license

http:// creativecommons.org/licenses/ by-nc-nd/4.0/

Based on a work at http://dx.doi.org/10.1016/j.scitotenv.2017.05.226

Please, cite as: Goetz, Renan-Ulrich; Martínez, Yolanda; Xabadia, Angels (2017)

"Efficiency and acceptance of new water allocation rules - The case of an agricultural water users association", Science of the Total Environment 601-602: 614-625 


\section{Graphical Abstract}

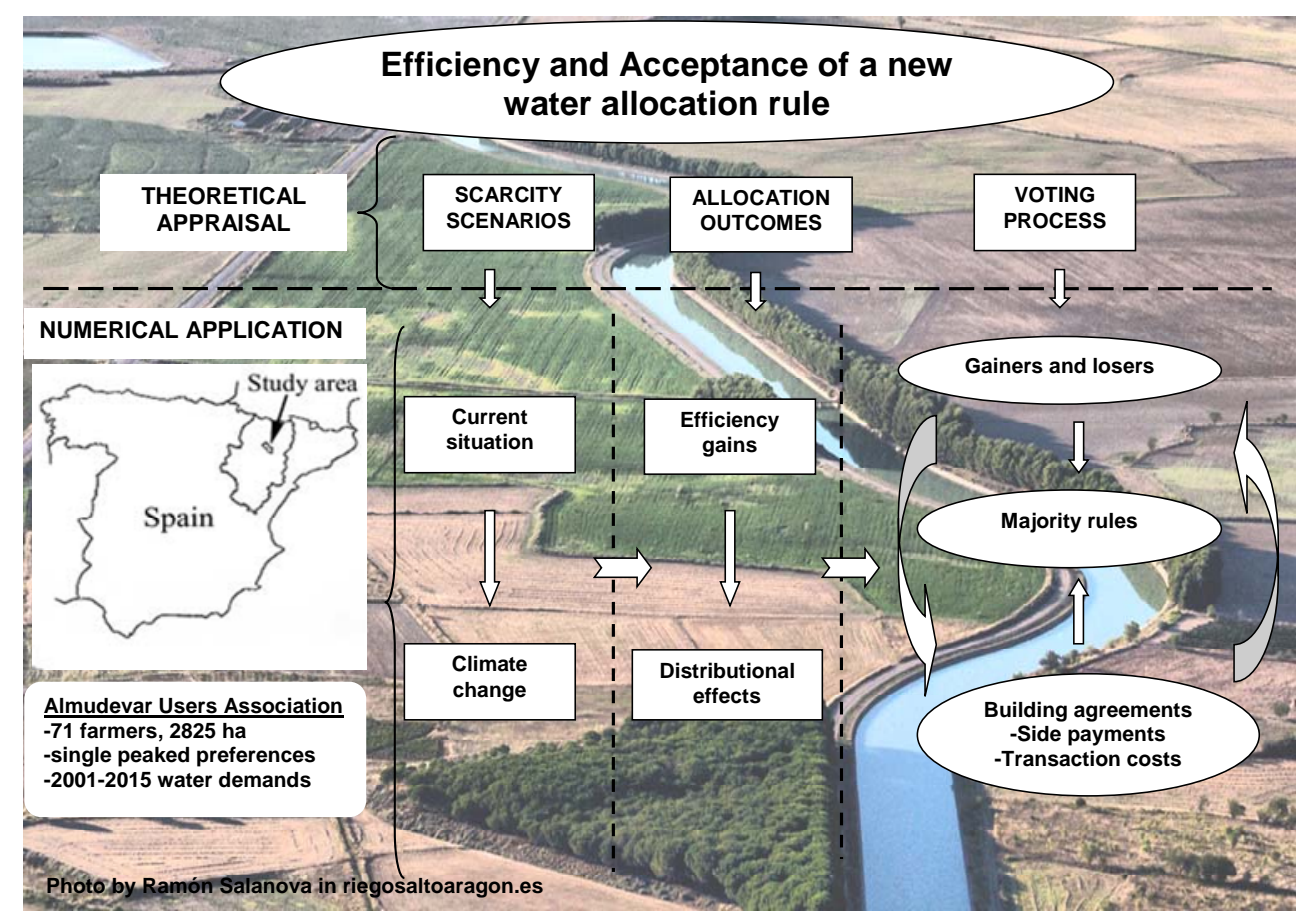

Keywords: social choice, voting, water allocation, agriculture, allocative efficiency

\section{Highlights:}

- Collective decision making (social choice) and the definition of water allocation rules in agriculture

- Water allocation rules based on social choice theory improve economic allocative efficiency without introducing distributional inequality

- The voting system of water users association often does not support the adoption of new water allocation rules

- Very small side payments are able to tip the balance towards the adoption of a new water allocation rules in the voting process. 


\section{Introduction}

Water scarcity and droughts in Europe, measured in terms of the water exploitation index $(\mathrm{WEI})^{1}$, are an increasing phenomenon that affects at least $11 \%$ of its population and $17 \%$ of its territory (European Commission, 2010). Water resources in Cyprus, Bulgaria, Belgium, Spain, Italy and Malta are exposed to constant water stress as these countries are currently using up 20\% or more of their long-term supplies every year (WEI > 20\%).

In Spain, for instance, the demand for water for irrigation purposes is about 15,000 $\mathrm{Hm}^{3}$ per year and represents about $80 \%$ of the total national consumptive demand. Water scarcity is extreme in river basins such as the Segura, Júcar, Sur, and the upper Guadiana river (INE, 2016).

Water scarcity and droughts are expected to increase in the nearby future as consequence of the concurrence of a variety of factors (European Commission, 2015). On one hand, the consumptive use of water is likely to increase as a result of the expansion of irrigated land, the intensification of tourism and higher transpiration ratios of the crops due to climate change. On the other hand, the amount of available water is likely to decrease in the wake of a decrease in precipitations as well as a change of its seasonal and geographical patterns.

The increasing level of water stress along with a more demanding regulation of the groundwater and surface water bodies at the European level (Water Framework Directive (European Commission, 2000), motivated and obliged the member states of the European Union to promote water management practices that allow to accomplish a "good status" of all surface water, groundwater and coastal waters in terms of quality and quantity (Albiac et al., 2007).

Numerous studies have assessed the potential of water market, or of administrative water pricing where private and social costs are considered. Both approaches aim at balancing demand and supply of water and sustaining the efficient use of water, i.e. allocate water such that it provides the highest social welfare. Traditionally, the establishment of markets has been considered as a measure that allows allocating water among users in a decentralized manner and attenuates the effects of water scarcity. Similarly, administrative water pricing allows reducing the demand of water but there is

\footnotetext{
${ }^{1}$ The water exploitation index (WEI) indicates the amount of water abstracted each year as a proportion of total long-term freshwater resources. It is an indicator of the pressure or stress on freshwater resources. A WEI above $20 \%$ implies that a water resource is under stress, and values above $40 \%$ indicate severe water stress and clearly unsustainable use of the water resource.
} 
no guarantee that the chosen price maximizes social welfare - simply because the supply side is taken account of, but not the demand side. However, the existing economic literature shows that water markets offer the most efficient allocation of water and maximize the social welfare (Howe et al., 1986; Easter and Hearne, 1995; Lee and Jouravlev, 1998).

The experience with water market is however distant from the theoretical ideal. In some cases, for example in the Murray-Darling basin in Australia (Bjornlund, 2003), the introduction of water markets even worsened the efficiency of water allocation. The reasons behind the failure of water markets are complex. It may be caused by the existence of political, institutional and/or physical barriers, which prevent vivid exchanges between sectors (Carey et al., 2002). Similarly, high transaction costs may be behind the difficulties in developing local water markets (Easter et al., 1998). Moreover, bureaucratic and legal problems, such as poorly defined water rights, may also prevent the functioning of water markets (Calatrava and Garrido, 2005). If functioning markets cannot be introduced or developed, allocation rules proposed in the literature of social choice may be a good alternative (Barberà, 2005). Goetz et al. (2005, 2008) analyzed the application of various allocation rules with Spanish data and concluded that their application could lead to significant water savings and improvements of the allocation efficiency.

A recent study of the Organization for Economic Cooperation and Development (OECD, 2015) states that besides water availability governance is a crucial issue for the management of water resources. According to the OECD (2015) poorly delineated multi-level governance structures and decision processes lead to an unclear allocation of roles and responsibilities. Consequently, improvements in water governance present a key challenge for better water management.

By the same token the adoption of the above mentioned allocation rules might not take place due to problems that are related to the process of collective decision making and water governance structures. Accordingly, this paper examines the conditions under which these allocation rules improve the allocation efficiency and are likely to be adopted by the members of an agricultural water users association. For this purpose, the study determines the number of gainers and losers and their associated gains and losses if these allocation rules were adopted. It also analyzes to which extent the gains and losses of the different farmers affect the outcome of the collective decision process to adopt or not a new water allocation rule. Based on the literature on the formation of 
coalitions (Serrano, 2004; Feldman and Serrano, 2006) we analyze if gainers can build agreements with side payments that provide incentives for the majority of the farmers to form part of an agreement to adopt a new water allocation rule. An empirical analysis based on the water allocation of the Almudevar irrigation district in the Ebro basin provides insights into driving factors for the acceptance or rejection of a new water allocation rule. Our study aims to contribute to the OECD' Principles on Water Governance that encourage evidence-based assessment of the distributional consequences of different water allocation rules (OCDE, 2015).

The results show that there exist water allocation rules that in terms of water allocation efficiency are always superior to the existing water allocation rule. However, if there is a moderate or severe drought only one of these rules is superior to the existing rules. The analysis of the decision process of the Almudevar irrigation district shows further that the established voting process would support the adoption of the most efficient water allocation rule provided that a small part of the overall gains is used to compensate the losers. Moreover, the adoption of the new water allocation rule does not lead to an increase in inequality between farmers.

The paper is organized as follows. Section 2 describes the theory of voting and allocative efficiency. Section 3 explains the method and data used for the empirical study. Section 4 presents the results obtained, and section 5 closes out the paper by presenting some conclusions.

\section{Theory of voting and allocative efficiency}

Collective decision making has been analyzed intensively in the economic literature. The results show that if side payments are permitted it is always possible to achieve allocative efficiency. It guarantees that the outcome provides the highest social welfare which in turn allows the gainers to compensate the losers (side payments) without using up all of their gains. Yet, it is an open question to which extent this general result still holds if the governance structure and the decision process itself are taken into account. The large diversity of governance structures and rules of decision processes foreclose the possibility to obtain a general answer to the question. Thus, one is left with the analysis of specific situations. For the case of water management and the acceptance of new allocation rules we concentrate on the most decisive characteristics of the collective decision process: the number of votes per person (governance structure) and the voting process (rules of the decision process). 
An early finding in the field of cooperate governance and the efficiency of takeovers of a firm was that the rule "one vote one share" will produces efficient outcomes if several bidders compete (Burkhart and Lee, 2008; Grossman and Hart; 1980, Grossman and Hart, 1988; Harris and Raviv, 1988). In a more recent article Dekel and Wolinsky (2012) confirm this rule, and establish that vote buying may improve efficiency provided that votes and shares are traded simultaneously. The simultaneous trade of votes and shares guarantees that all voters have the same interests i.e. they form a homogenous group.

In the context of water management, however, there does not exist an analog for shares. Yet, the notion of shares suggests that vote buying would improve efficiency if the party who tender their votes receive additional future benefits from the adopted policy by the party who won the voting. In fact, this situation may arise when the available water is managed by a general assembly of the farmers. The general assembly may establish rules which control the future access to the resource. Each specific rule that defines future water allocation presents future benefits that accrue to the individual members of the WUA. In consequence the land values of the farmers are likely to increase or decrease depending on the allocated water rights. In this respect land values can be viewed as shares influenced by water allocation rules and the net benefits that accrue from the use of the water can be considered as the profits that the shareholder is entitled to. Hence, decisions of the general assembly that distribute a given amount of water in one way or the other (water allocation rule) can be viewed as an exchange of shares. Based on the analogy between shares and land values we analyze to what extent vote buying would improve efficiency in the context of water management taken into account the voting rule and the number of votes per farmer.

With respect to the number of votes per person Dekel and Wolinsky assume that all shares have identical voting rights. While this assumption is mostly correct in the field of cooperative government it is not in the field of water management. Our analysis considers the fact that the number of votes per person is frequently linked to the number of hectares owned by the farmer. This peculiarity of many WAU is not only important for the voting process but also for the determination of the side payments. Moreover, and in contrast with the study by Dekel and Wolinksy, we consider not only a decision rule based on the simple majority but also on the qualified majority.

Vote buying may be considered as immoral or political incorrect. Yet, in reality it is a frequent practice. Of course, often it does not occur in form of money transfer but in 
form of negotiating the characteristic of the proposal to be voted. It is possible to include clauses, exceptions, and criteria etc. that favor or harm certain groups of agents so that it conditions the vote of the farmer.

\section{Materials and Methods}

The previous theoretical results will be tested empirically by using real data from a Spanish irrigation district whose main characteristics are described in this section. Data collected will be incorporated in a farm economic model to evaluate the effect of different water allocation rules and to determine the farmers' responses.

\subsection{Area of study}

The area of our numerical application is located in the medium Ebro Valley at $18 \mathrm{~km}$ of Huesca in Aragón (Spain) (see Fig. 1). The climate of the zone is Mediterranean, with an annual average precipitation of $430 \mathrm{~mm}$, and an average annual temperature of $13.8^{\circ} \mathrm{C}$.

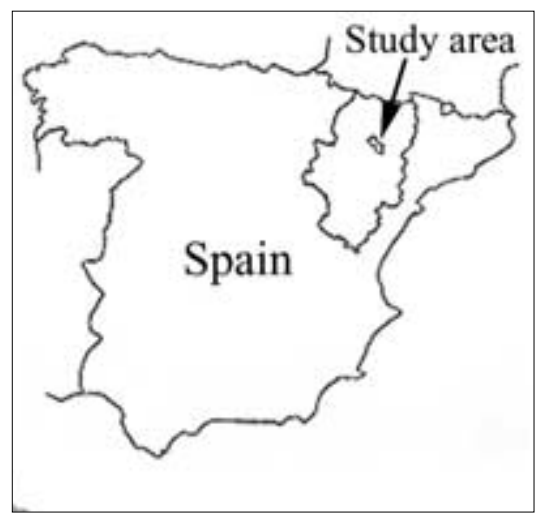

Fig. 1. Map of the location of the study area

The Almudevar irrigation district is representative of one of the numerous traditional irrigation districts of the country. The Almudevar Water Users Association (WUA) is located in the province of Huesca, in the northeast of Spain. The total district area covers 3825 ha, with 3674 ha irrigated land.

The WUA was developed for irrigation in the 1950s, and was designed to apply supplementary irrigation to winter cereal crops. Water demand in the area has increased since the 1970s due to changes in cropping patterns. In 2008 began the modernization process of the district by changing surface to sprinkler irrigation. Traditionally, the most important crops have been winter cereals (wheat and barley) (58.8\%), corn (19.4\%) and alfalfa (20.6\%), followed by other such as sunflower, rice, fruit and orchard to a lower 
extent (Torres, 1983). In the years before the modernization (2008-2009) of the WUA the crop pattern had become more intensive, growing predominantly summer crops (Barros et al., 2011). After modernization (2011) corn has become the dominant crop (22\% as the single crop and $29 \%$ as second crop) with alfalfa (22\%) and winter cereals (17\%).

The Almudevar WUA has been studied recently by Barros et al. (2011) and Jiménez-Aguirre and Isidoro (2012) to explore the effects of the modernization process on cropping patterns and farmers' inputs management. For this purpose, a representative sample of farmers was surveyed in person from the years 2001 to 2015. In fact, although the WUA has 615 members, only about 71 of them cultivate their own land and the rest of WUA members rents their land to these farmers. Therefore, the main cropping and managing decisions are in the farmers' hands that cultivate their own land. In addition, data were collected on allocated water to the WUA and per hectare allocation within the WUA for the years 2001 to 2015.

A total of 71 surveys were conducted where information about crop selection, tillage, inputs use (water and fertilizer), were collected. This information is used here to define the characteristics of the 71 farmers considered and to calculate their benefit functions in order to evaluate the efficiency of the social rules and the possibility of adopting a new rule according to the outcome of the collective decision process (voting). For the purpose of our empirical application, we have selected the data of the main crops in the area: winter cereals wheat and barley (irrigated and not irrigated), corn, pea, alfalfa and sunflower. These selected crops covered 2348.5 ha in 2014 (62\% of the total cultivated area). Table 1 shows the distribution of main crops covered by the surveys.

Table 1. Distribution of main crops

\begin{tabular}{ll}
\hline Crop & Acreage (ha) \\
\hline Irrigated winter cereal & 206.7 \\
Non irrigated winter cereal & 1672 \\
Corn & 124.5 \\
Alfalfa & 109.25 \\
TH_Corn ${ }^{1}$ & 207 \\
TH_Sunflower ${ }^{2}$ & 29 \\
Total & 2348.5 \\
${ }^{1}$ TH_Corn corresponds to two harvests per year: cereal/others after corn \\
${ }^{2}$ TH_Sunflower corresponds to two harvests per year: cereal after sunflower
\end{tabular}




\subsection{Description of the Almudevar Users' Association organization}

The key decisions about water management are taken jointly by the two institutions operating within the watershed: the watershed regulatory authority (in our case Confederación Hidrográfica del Ebro, CHE) and the Almudevar Water Users Association. These institutions determine the water allocation for each user, set the administrative water price, assign the irrigation turns, and control investment in the physical infrastructure and individual water consumption or transfer to other users. The available water is assigned to each irrigation district in proportion to the size of the district. Likewise, the WUA assigns the water to each farmer in proportion to the amount of land cultivated by the farmer. Thus, the water is assigned according to the so called proportional rule and each farmer is assigned the same amount of water per hectare.

In our case, the statutes of the Almudevar WUA establish the internal operating rules of the community. These rules refer to decisions on the distribution of irrigation water among shareholders (farmers), decisions on new collective irrigation investments, acquisition of additional water (from external users), claims and complaints with respect to the irrigation management, economic budgets, etc. In addition, the statutes of WUA establish that any change in water use rights has to be supervised by the Ebro watershed regulator (CHE).

The internal decisions in WUA are made through the General Assembly (Junta General), where all the shareholders make decisions by voting. The Junta General adopts resolutions by absolute majority of present voters. The shareholders may be represented in the Junta General by other shareholders with a simple written permission, or by their administrators with a legal permission verified by a public notary.

The distribution of the number of votes in Almudevar WUA is presented in Table 2. Any farmer with an amount of land lower than 1 hectare can associate himself/herself with others to accumulate enough land in order to obtain the corresponding votes. The information of votes will be employed for our empirical illustration of collective decision making of the WUA about the acceptance of new water allocation rules. 
Table 2. Distribution of votes in the WUA

\begin{tabular}{cc}
\hline Number of hectares & Number of votes \\
\hline 1 & 1 \\
more than 1 to 5 & 3 \\
more than 5 to 10 & 4 \\
more than 10 to 15 & 5 \\
more than 15 to 20 & 6 \\
more than 20 to 40 & 7 \\
more than 40 to 80 & 8 \\
more than 80 & 9 \\
\hline
\end{tabular}

Fig. 2 shows the distribution of votes among the 71 farmers considered for our empirical application. Information of surveys indicates that the farmers with less than 20 hectares accumulate the majority of the votes (211 of 413) with a total extension of 511 hectares (21.7\% of the total area considered).

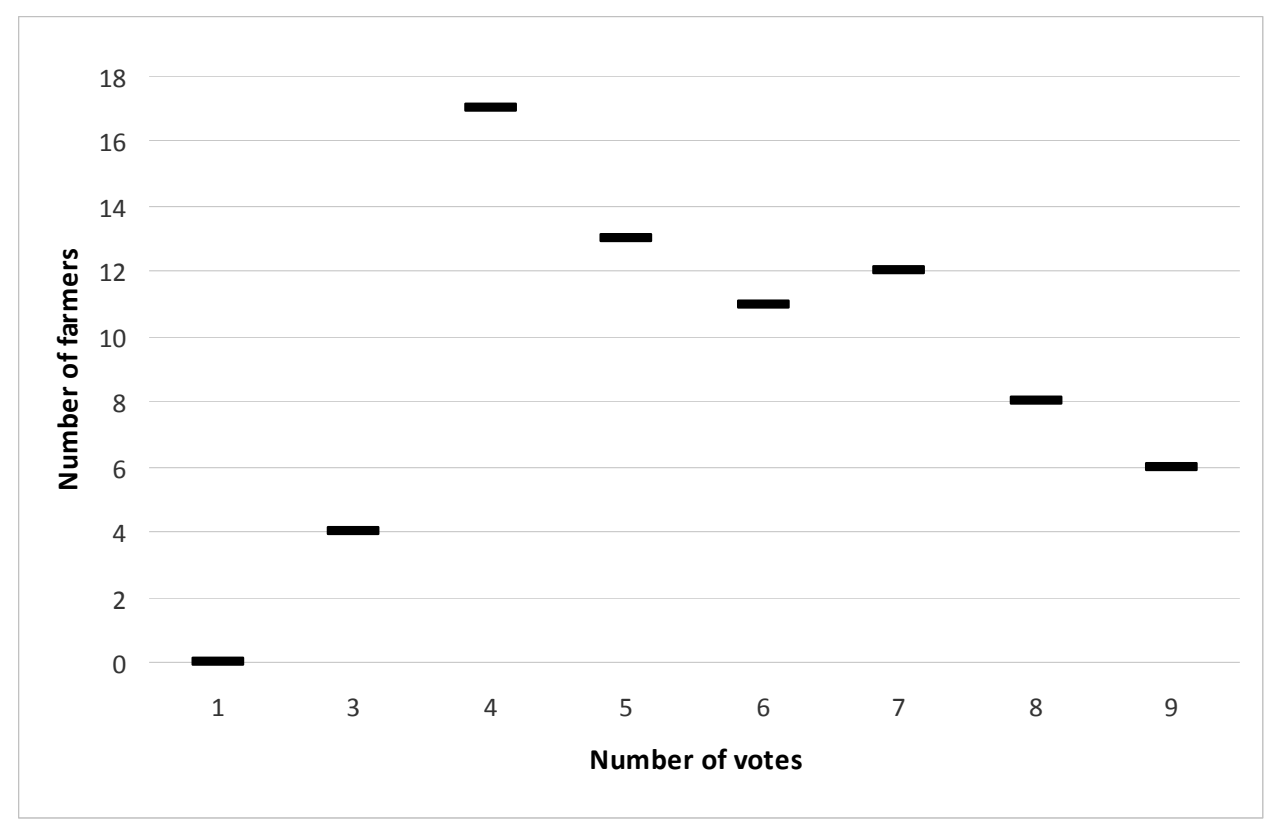

Fig. 2. Distribution of votes among Almudevar Users' Community

\subsection{Economic model}

The evaluation of the different rules for assigning water among farmers requires estimating the net benefit functions of farmers. As a first step we estimated the crop production functions for each crop using biophysical data, which were previously generated with the biophysical simulator EPIC (Environmental Policy Integrated Climate, Mitchell et al., 1998). The EPIC model is able to reproduce the biophysical processes in the soil and the process of plant growth as a function of the inputs and the 
weather. The model was calibrated to accurately reflect local conditions with respect to climate, soil, and the usual tillage and operation activities and the results were validated with the real observed data. All this information was collected by farm surveys.

The crop production functions $\hat{y}_{i}$, (t/ha) depend on water applied, following the polynomial specification:

$$
\hat{y}_{i}=a_{i 0}+a_{i 1} \cdot w_{i}+a_{i 2} \cdot w_{i}^{2}
$$

where $w_{i},\left(€ / \mathrm{m}^{3}\right)$ denotes the amount of water applied for crop $i$. In addition, we collected data of crop, fertilizer and seeds prices in order to calculate the net benefit functions for farmers. As a second step we employ the result of equation (1) for the determination of the farmer's net benefit function. The net benefits of farmer $j$ $(j=1, \ldots, 71)$, from production activities $i=1, \ldots, 7$ are given by the difference between farm returns and costs. The net benefit $\pi_{j}$ (in € per hectare) for farmer $j$ is calculated as follows:

$$
\begin{gathered}
\pi_{j}\left(E_{j}\right)=\max _{w_{i, j}, h_{i, j}} \sum_{i=1}^{7}\left(p c_{i} \cdot \hat{y}_{i, j}\left(w_{i, j}\right)-n_{i, j}-s_{i, j}-p_{j} \cdot w_{i, j}\right) \cdot h_{i, j} \\
\text { subject to: } \quad \sum_{i=1}^{7} w_{i, j} \leq E_{j} ; w_{i, j} \geq 0
\end{gathered}
$$

where $p c_{i}$ denotes the market price of crop $i(€ / \mathrm{tm})$, parameter $n_{i}$ is the fertilizer cost of crop $i(€ / \mathrm{kg})$ and $s_{i}$ denotes the seeds cost for crop $i(€ / \mathrm{tm})$. The variable $h_{i j}$ denotes the number of hectares cultivated with crop $i$. The function $\pi_{j}\left(E_{j}\right)$ determines the total net benefits of farmer $j$ given the administrative water price $p_{j}$ and his/her initial water endowment $E_{j}\left(\mathrm{~m}^{3} / \mathrm{ha}\right)$. The current value of parameter $p_{j}$ in the study area is 0.0475 $€ / \mathrm{m}^{3}$.

Finally, to estimate the net benefit functions for each farmer we varied the parameter $w_{i}$, between 0 and $11000 \mathrm{~m}^{3} / \mathrm{ha}$. From the values obtained for $\pi_{i}\left(E_{i}\right)$, we estimated a new function, denoted by $\hat{\pi}_{j}\left(E_{j}\right)$ that relates the $j$ farmer's net benefit obtained with the initial amount of water assigned.

$$
\hat{\pi}_{j}=b_{j 0}+a_{j 1} \cdot E_{j}+a_{j 2} \cdot E_{j}^{2}
$$

As shown in equation (3), the estimated farm benefit functions $\hat{\pi}_{j}\left(E_{j}\right)$ have a quadratic form. Their parameters were specified using the SHAZAM package (White, 2002). 
These estimated benefit functions were used to evaluate the allocation rules and to calculate the economic viability of economic compensations among users for impeding or facilitating changes of the allocation rules. Calculations were made using Mathematica (Wolfram Research, Inc., 2015).

For our empirical analysis, we first calculate the efficiency gains obtained by introducing two different allocation rules based on social choice theory in comparison with the proportional rule: the uniform allocation rule and the sequential allocation rule. The uniform rule was proposed initially by Sprumont (1991) and has the properties of anonymity, Pareto efficiency and strategy-proofness. The last property implies that agents cannot increase their allocations by misreporting their preferences, so they have no incentives to lie. Barberà et al. (1997) proposed the sequential allocation rule when there are asymmetries among the agents that need to be respected. Thus, the sequential rule maintains the last two properties but respects asymmetry.

The preceding social rules were defined and applied for the case of water allocation by Goetz et al. (2005, 2008) in the Flumen-Monegros irrigation district. In particular, the uniform rule starts with the allocation outcome from applying the proportional rule. However, it departs from the proportional allocation if there is a farmer or a group of farmers who demands less water than he/she/it is entitled to. In this case, the amount requested is allocated and the remaining water is available to be distributed equally among the rest of the farmers. This determines a new amount to be distributed proportionally. The former procedure is repeated until there are no farmers whose ideal amount of water, i.e. the amount of water that maximizes his/her net benefits is less than or equal to their newly assigned amount. In contrast to the proportional and uniform rules, the initial assignments of the sequential rule are not identical but take into account the heterogeneity of farmers. In our case, water is distributed according to the farmers' net benefit when there is no scarcity. The appendix provides an example to illustrate the operation of the two allocation rules. A more complete exposition of the functioning of social rules is found in Goetz et al. (2008).

After these intuitive explanations, we will state the specific procedure to evaluate each rule. The efficiency gains of any allocation rule is calculated by comparing the sum of the net benefits of the farmers resulting from the application of the current proportional allocation rule and the newly designed uniform and sequential rules with the farmers' net benefits resulting from the introduction of a water market within the same water users association. Thus, we take the outcome of the water market as a 
benchmark for a comparison with respect to the outcomes of the proportional rule, the uniform rule and the sequential rule.

Once we calculated each farmer's gains or losses from changing the current proportional rule to a new allocation rule, we examined other aspects that influence its acceptance and implementation. Specifically, the identification of gainers and losers permits to calculate the number of votes and the side payments that are required for having sufficient support in the voting process. Another relevant aspect is the role of transaction costs as an impediment of changing the status-quo. Finally, we examine the robustness of our results with respect to changes in the climatic conditions. For this purpose, we consider the effects of climate change on the allocative efficiency and acceptance of the social rules.

\section{Results and Discussion}

In this section, we analyze the functioning and characteristics of allocation rules established in the previous section. We focus on four key aspects that could affect the acceptance and implementation of a new rule in the context of the Almudevar WUA: i) allocative efficiency, ii) distribution of gains and losses among users and its influence in the voting process, iii) effects of the existence of transaction costs and iv) impact of climate change.

\subsection{Efficiency of the rules}

In a first stage, the allocation rules have been implemented by simulating increasing water scarcity situations (from 0 to $50 \%$ with respect to the sum of ideal shares of all members) in order to evaluate their allocative efficiency. The efficiency losses of rules are measured as a percentage of the benefits with respect to the most efficient outcome resulting from the introduction of a water market. Fig. 3 reveals that the implementation of the sequential rule leads to lower net benefit losses than the proportional and uniform rules. The uniform rule is superior to the proportional as long as water reduction is inferior to $30 \%$. Thereafter the net benefit losses are identical to the ones of the proportional rule. Hence, the analysis shows that applying the sequential rule in the case of droughts provides the opportunity to reduce efficiency losses associated with the proportional and uniform rules. This result is in accordance with previous finding of Goetz et al. (2008) in other irrigation areas. 


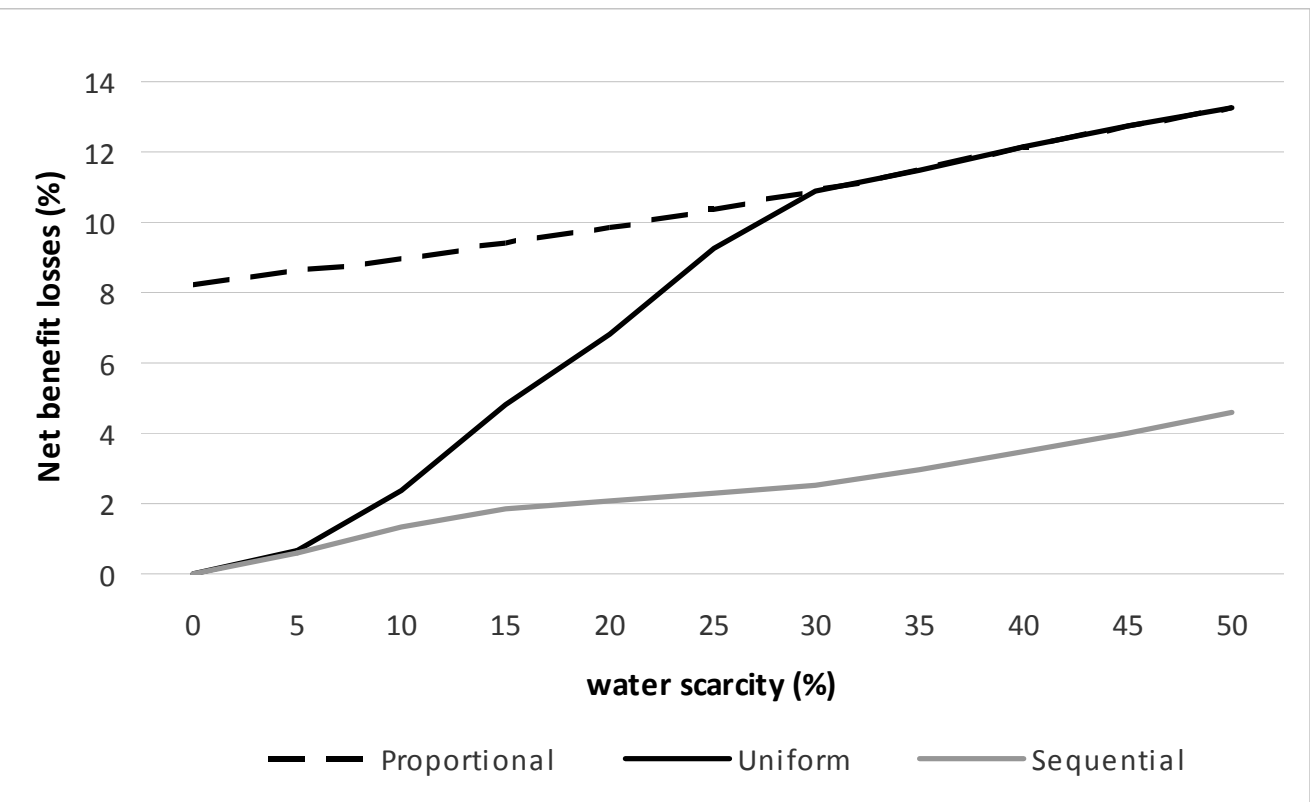

Fig. 3. Net benefit losses of the rules with respect to outcome of a water market (\%)

In a second stage, the rules are implemented and the real water endowments for the years 2001 to 2015 were considered. This ex-post analysis allows evaluating their effect on the efficiency under real conditions. The data show that only two of the last 15 years were especially dry (2009 and 2010) while there was no water scarcity in the other years. In the year 2009 severe restrictions were in place, cutting the total amount of allocated water by $63 \%$ of the water demanded. The subsequent year, 2010, was a year of moderate drought, where the available water was equal to $68 \%$ of the total requested amount.

Fig. 4 depicts the effect of scarcity on water allocations among users for the allocation rules examined. We illustrate the implementation of the rules considering three scenarios of water scarcity: non-scarcity (regular), moderate scarcity (2010) and severe scarcity (2009). In addition, three different farms have been selected to show how the social rules affect the farms' assigned water shares in the case of the water scarcity. Let consider farms number 1, 7 and 12 whose demand that maximizes their net benefits (ideal shares) are 2385, 7914 and $4682 \mathrm{~m}^{3} /$ ha respectively. Under the current proportional rule, all farms receive the same portion of water. In a regular year, only the farmer's demand that is below the proportional allocation $\left(3252 \mathrm{~m}^{3} / \mathrm{ha}\right)$ is satisfied. It results in an inefficient allocation, since excess water of some farmers is not used. 


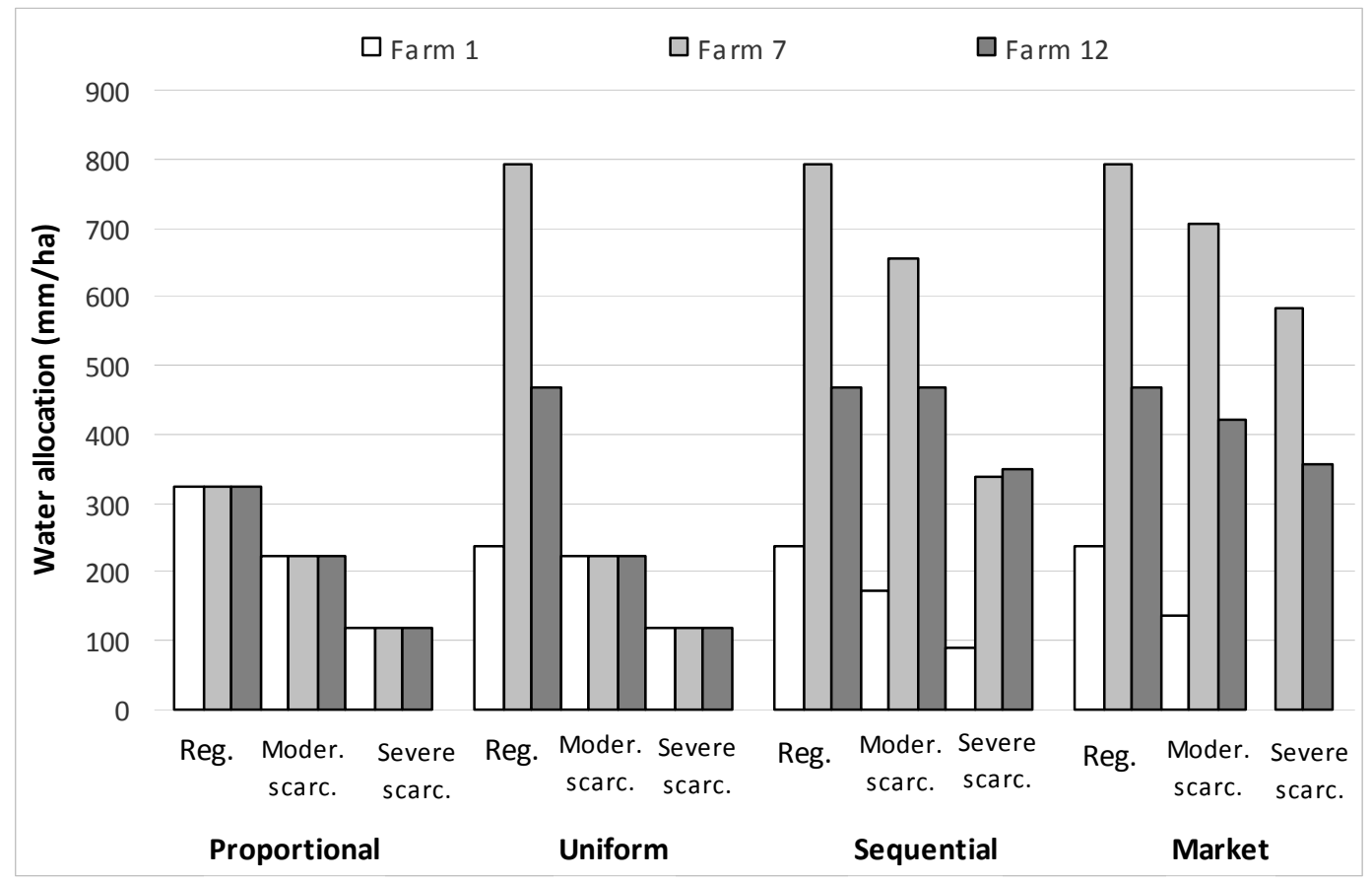

Fig. 4. Water allocation according to four different mechanisms for three different farms based on real water endowments.

When no scarcity exists (regular years), the proportional rule is less efficient (8\%) than the market outcome, while the social rules (uniform and sequential) are as efficient as water markets since all farmers obtain their ideal shares. In these periods, total net benefits from agriculture sump up to 1.75 million $€$ when the proportional rule is applied, ${ }^{2}$ while the net benefits would increase to 1.91 million $€$ if either the uniform or sequential rule were implemented. The efficiency losses of social rules would be insignificant while the application of proportional rule implied losses around $8 \%$ of the benefit. Hence, with no water scarcity, social rules lead to better outcomes than the currently applied proportional rule.

In the case of moderate and severe water scarcities, Fig. 4 illustrates for farms 1, 7 and 12 that the uniform and proportional rules lead to the same allocations, while the sequential rule leads to an allocation that is close to the market outcome. Under moderate scarcity, only farm 12 receives its ideal share if the sequential rule is applied. However, in the case of severe scarcity all farms are assigned an amount of water that is below their ideal share. The efficiency losses of the proportional and uniform rules reach $11 \%$ and $14 \%$ in years of moderate and severe scarcity respectively while the losses of the sequential rule are $2.6 \%$ and $5.4 \%$.

\footnotetext{
${ }^{2}$ Monetary values are not presented in graphical form to keep the presentation short.
} 
Table 3 presents the total discounted net benefits of the Almudevar WUA over the last 15 years for the four different allocation mechanisms calculated for the years 20012015. It demonstrates that the efficiency losses of the uniform rule are much smaller than the one of the proportional rule. It also demonstrates that the efficiency of sequential rule is similar to that of the water market.

Table 3. Discounted net benefits over 15 years (2001-2015), calculated with a discount rate of $3 \%$.

\begin{tabular}{lcc}
\hline Allocation rule & $\begin{array}{c}\text { Discounted net benefits } \\
\text { (thousand } € \text { ) }\end{array}$ & $\begin{array}{c}\text { Efficiency losses } \\
\text { (\%) }\end{array}$ \\
\hline Proportional rule & 20772 & 8.76 \\
Uniform rule & 22431 & 1.47 \\
Sequential rule & 22659 & 0.47 \\
Market & 22766 & - \\
\hline
\end{tabular}

Thus, the sequential rule becomes the most interesting rule for analyzing the outcome of the voting processes, the effect of side payments and its distributional effects among farmers. Hence, the rest of the analysis in this section will focus on comparing the sequential rule with the uniform rule, where the later one will be considered the status quo situation.

\subsection{Distributional effects}

Apart from efficiency, distributional justice is an important factor for acceptance or non-acceptance of the rules. Fig. 5 compares the distributional effects of the two rules, for a rising level of water scarcity. Fig. 5a) shows the values of the Gini Index ${ }^{3}$ with respect to net benefit per hectare while Fig. 5b) shows the Gini Index with respect to the total net benefit of the farm. As expected, the sequential rule implies an increase in the differences in the net benefit per ha between farms since water is assigned to favor the more efficient users (see Fig. 5a). However, when the Gini index is calculated with respect to the total net benefits Fig. 5b) shows a somewhat counterintuitive result. The application of the sequential rule leads to a lower Gini index compared to the uniform rule when scarcity reaches more than $30 \%$. The explanation is that under water scarcity

\footnotetext{
${ }^{3}$ The Gini Index (or Gini coefficient) is a measure of statistical dispersion initially intended to measure inequality between the country's residents. It is the most commonly used approach to measure the inequality among values of a frequency distribution, where a value of 0 indicates equality and a value of 1 perfect inequality.
} 
the sequential rule favors small farms whereas larger farms benefit less since they produce mainly on lands of poor quality.

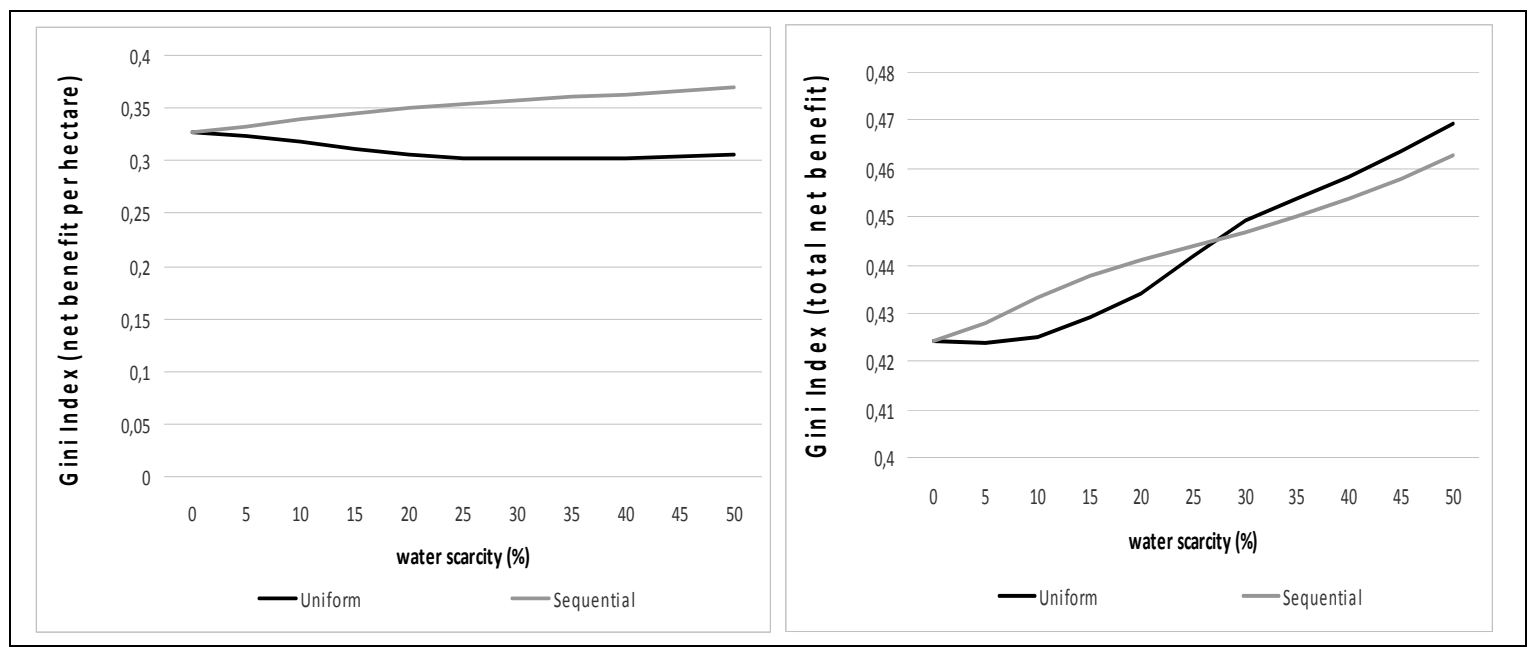

Fig. 5. Distributional effects of the water allocation rules. a) Gini Index with respect to the net benefit per hectare. b) Gini Index with respect to the total net benefits

\subsection{Voting process and side payments}

Three voting methods have been explored in order to evaluate in which way the sequential rule is accepted by users and how the new rule affects the distribution of benefits among users. The voting processes considered are: “one person-one vote”, “one hectare-one vote", and finally the real voting method established by the statutes of WUA Almudevar. In addition, two alternative majorities will be considered: the simple majority of the votes ( $50 \%$ of votes +1$)$ and the qualified majority of two-thirds of the votes (66.6\% of votes). Farmers who obtain higher (or equal) profits under the sequential rule are supposed to vote for a change, otherwise they vote for the status quo (uniform rule). One expects that the likelihood of the approval depends on the distribution of gains and losses among the users of the water association.

Simulations of water reductions from $0 \%$ to $50 \%$ as shown in Fig. 6 reflect that the sequential rule obtains a decreasing percentage of votes as water scarcity increases. This means that the higher the water scarcity, the more farmers lose with a change. Thus, they vote for the status quo. These results indicate that the voting method crucially affects the implementation possibilities of the sequential rule. In fact, when water scarcity is higher than $15 \%$ and simple majority is required, the sequential rule would only be adopted if the "one person-one vote" method were in place. However, if a qualified majority was needed, any water scarcity higher than $10 \%$ would impede the 
approval of the new rule under whatever ponderation of the votes. Hence, the "one person-one vote" system favors the change to the sequential rule in the presence of scarcity while " 1 ha- 1 vote" and the current voting system tends to preserve the status quo.

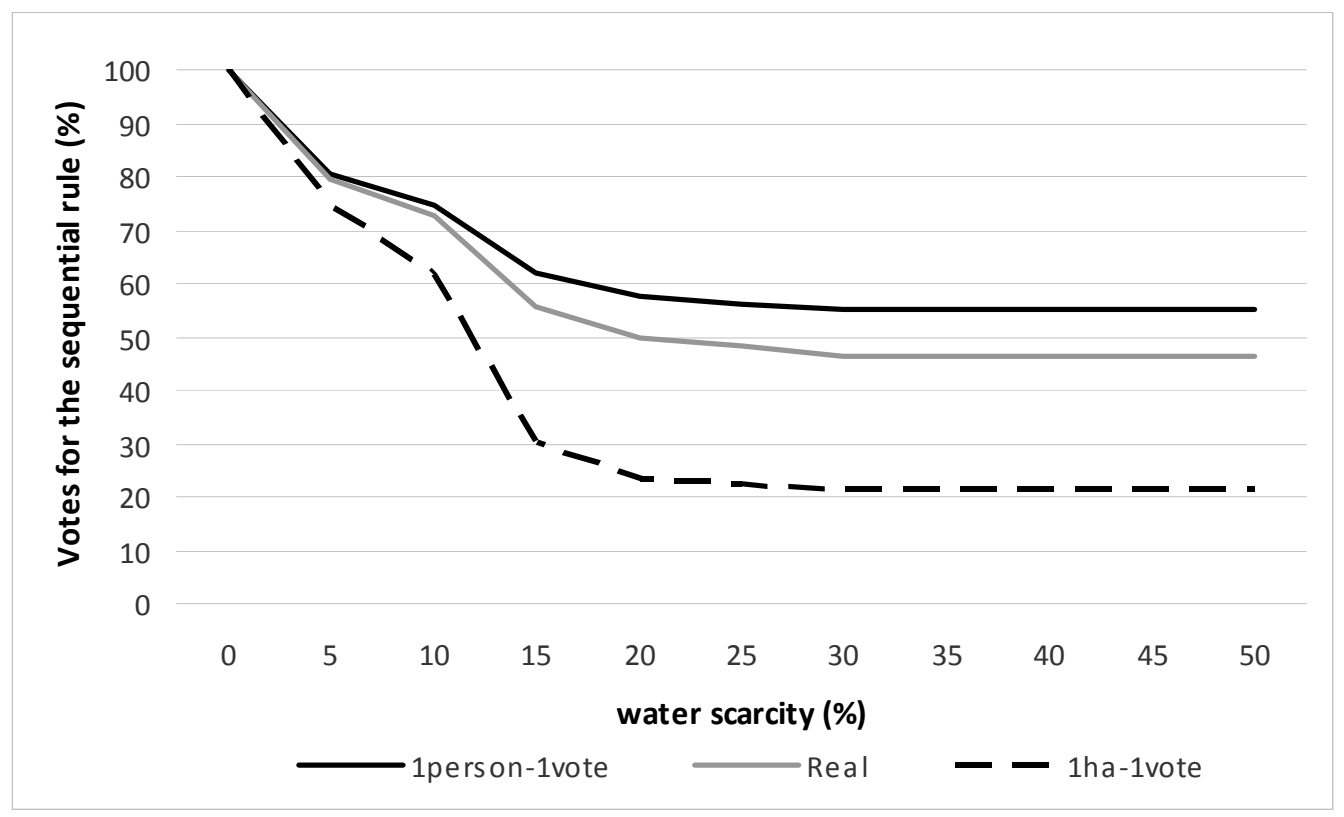

Fig. 6. Percentage of votes for the adoption of the sequential rule.

Results with real water allocations during the last 15 years confirm the previous claim: The sequential rule is voted unanimously in regular years independently of the voting method. However, under water scarcity (years 2009 and 2010), the ponderation of the votes has a strong effect on the probability to approve the sequential rule. In fact, only with "one person-one vote” the sequential rule obtains the simple majority of votes in both years (54.9\%) while with "one hectare-one vote" and current voting only $46.4 \%$ and $21.5 \%$ of users vote for the change (Table 4). Status quo will always be maintained in years of water scarcity with qualified majorities under whatever voting method. Thus, although the sequential rule improves the total net benefits, the degree of water scarcity and the type of majority rule may prevent its adoption due to the distribution of gains and losses among farmers.

Next we analyzed voting processes in more detail by examining their effects on the required number of votes and side payments for adopting the sequential rule. We considered the case where change voters (gainers) have the possibility to purchase additional votes from the opposite party. To make payments between users, it is assumed that change voters can identify users with the lowest net benefit losses and that 
the change voters are willing to compensate them for tendering their votes in exchange for payments. Table 4 shows the calculations of votes and payments for the specific cases of a moderate drought (2010) and a severe drought (2009). The side payments are always necessary under the qualified majority rule and payments are lower with "one person-one vote" as the number of votes to buy is also lower. After realizing side payments among users it is possible to determine that the total net benefits of the new rule remain positive. When side payments are permitted, the sequential rule would have an opportunity to be implemented for all analzyed voting methods. With a required qualified majority, payments would represent 0.005 to $5.98 \%$ of total gains in years with moderate scarcity and 1.34 to $13.1 \%$ in years with severe scarcity.

Table 4. Voting methods and side payments for change.

\begin{tabular}{|c|c|c|c|c|c|c|c|}
\hline \multirow[t]{2}{*}{$\begin{array}{l}\text { Ponderation } \\
\text { of votes }\end{array}$} & \multirow[t]{2}{*}{$\begin{array}{l}\text { Majority } \\
\text { rule }\end{array}$} & \multirow{2}{*}{$\begin{array}{l}\text { Total \# } \\
\text { of } \\
\text { votes }\end{array}$} & \multirow{2}{*}{$\begin{array}{c}\% \\
\text { Votes } \\
\text { for } \\
\text { change }\end{array}$} & \multirow{2}{*}{$\begin{array}{c}\text { Voting } \\
\text { results } \\
\text { without } \\
\text { side } \\
\text { payment }\end{array}$} & \multirow{2}{*}{$\begin{array}{c}\text { Votes to } \\
\text { buy } \\
\text { for } \\
\text { change }\end{array}$} & \multicolumn{2}{|c|}{$\begin{array}{c}\text { Payments for change }(€) \\
\text { (\% over total } \\
\text { efficiency gains) }\end{array}$} \\
\hline & & & & & & $\begin{array}{c}\text { Moderate } \\
\text { scarcity }\end{array}$ & $\begin{array}{l}\text { Severe } \\
\text { scarcity }\end{array}$ \\
\hline \multirow{2}{*}{$\begin{array}{c}1 \text { pers-1 } \\
\text { vote }\end{array}$} & $\mathbf{S M}^{1}$ & 71 & 54.92 & Seq. & - & 0 & 0 \\
\hline & $\mathbf{Q M}$ & 71 & 54.92 & St-quo & 9 & $\begin{array}{l}827.22 \\
(0.0054)\end{array}$ & $\begin{array}{c}1860.72 \\
(1.34)\end{array}$ \\
\hline \multirow{2}{*}{ Real } & SM & 413 & 46.48 & St-quo & 15 & $\begin{array}{c}33.58 \\
\left(2.19 \cdot 10^{-4}\right)\end{array}$ & $\begin{array}{c}127.86 \\
\left(9.15 \cdot 10^{-4}\right)\end{array}$ \\
\hline & $\mathbf{Q M}$ & 413 & 46.48 & St- quo & 84 & $\begin{array}{c}2421.54 \\
(1.61)\end{array}$ & $\begin{array}{c}4783.67 \\
(3.54)\end{array}$ \\
\hline \multirow{2}{*}{$\begin{array}{l}1 \text { ha-1 } \\
\text { vote }\end{array}$} & SM & 2340 & 21.58 & St-quo & 666 & $\begin{array}{c}4113.27 \\
(2.75)\end{array}$ & $\begin{array}{c}8789.91 \\
(6.70)\end{array}$ \\
\hline & $\mathbf{Q M}$ & 2340 & 21.58 & St-quo & 1055 & $\begin{array}{c}8652.08 \\
(5.98)\end{array}$ & $\begin{array}{c}16183.29 \\
(13.09)\end{array}$ \\
\hline
\end{tabular}

${ }^{1}$ SM: simple majority; QM: qualified majority;

We also analyzed the effect of different voting methods on the distributional justice for the application of the sequential rule. The results are presented in Fig. 7 in form of the Gini Index with respect to total net benefit. When simple majority is required (Fig. 
7a), voting processes have no effect on the total benefit distribution among users. On the contrary, the requirement of a qualified majority affects distributional justice if the scarcity is larger than $10 \%$. In these situations, real voting method leads to a slightly more equalitarian distribution of the net benefits.

From the analysis of Gini Index we can affirm that side payments have a limited effect on distributional effects of voting methods whatever majority requirement is imposed.

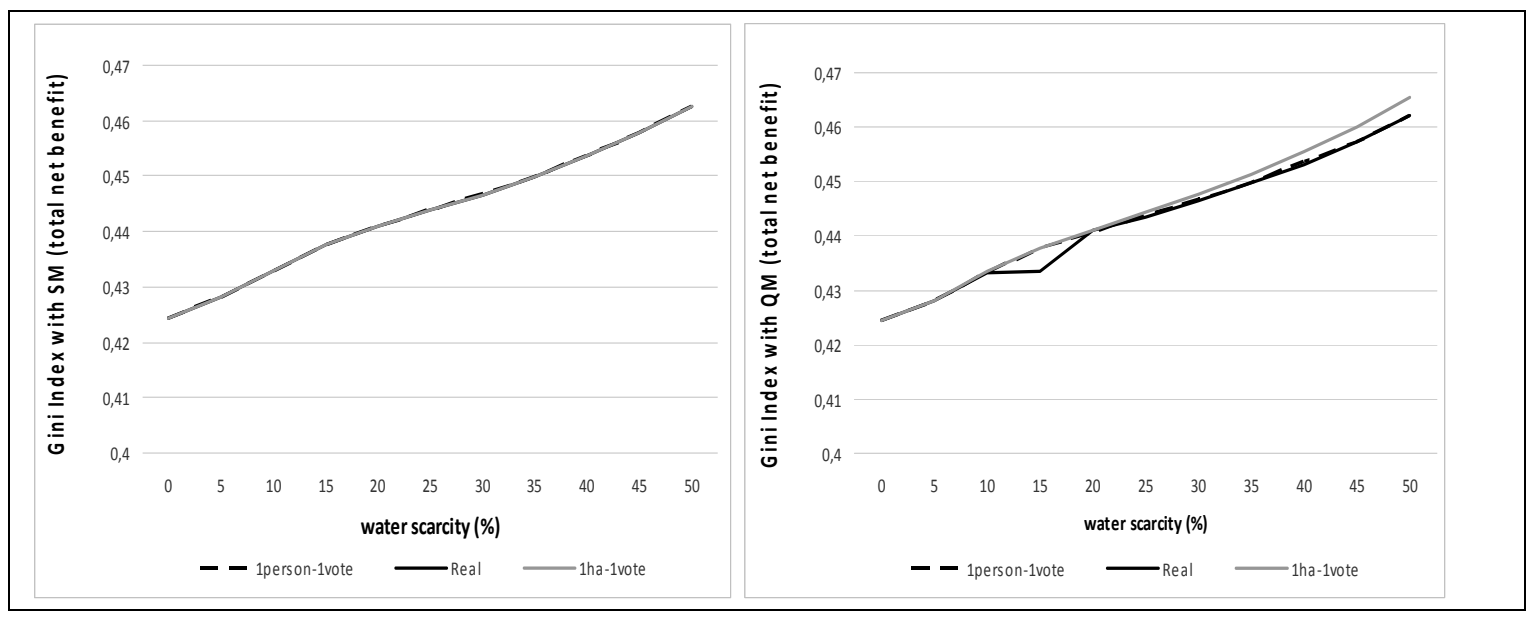

Fig. 7. Distributional effects of different voting methods. a) Simple majority, b) Qualified majority

\subsection{Transaction costs}

A determining factor for the implementation of a new water allocation rule may be the level of transaction costs. If they are sufficiently high, they may annihilate all gains, which render the application of social rules useless. In the context of the studied water users association, transaction costs include ex-ante costs of drafting and negotiating agreements, and the ex-post costs associated with verification and enforcement of contracts. In this section the effect of transaction costs on the private gains are assessed by simulating rising levels of these costs from 0 to $2000 €$ per farmer who received a side payment. Fig. 8 illustrates the benefits gains of change when transaction costs are considered in year 2009 (severe scarcity case). The benefits are expressed in percentage with respect to benefit gains when there are no transaction costs. 


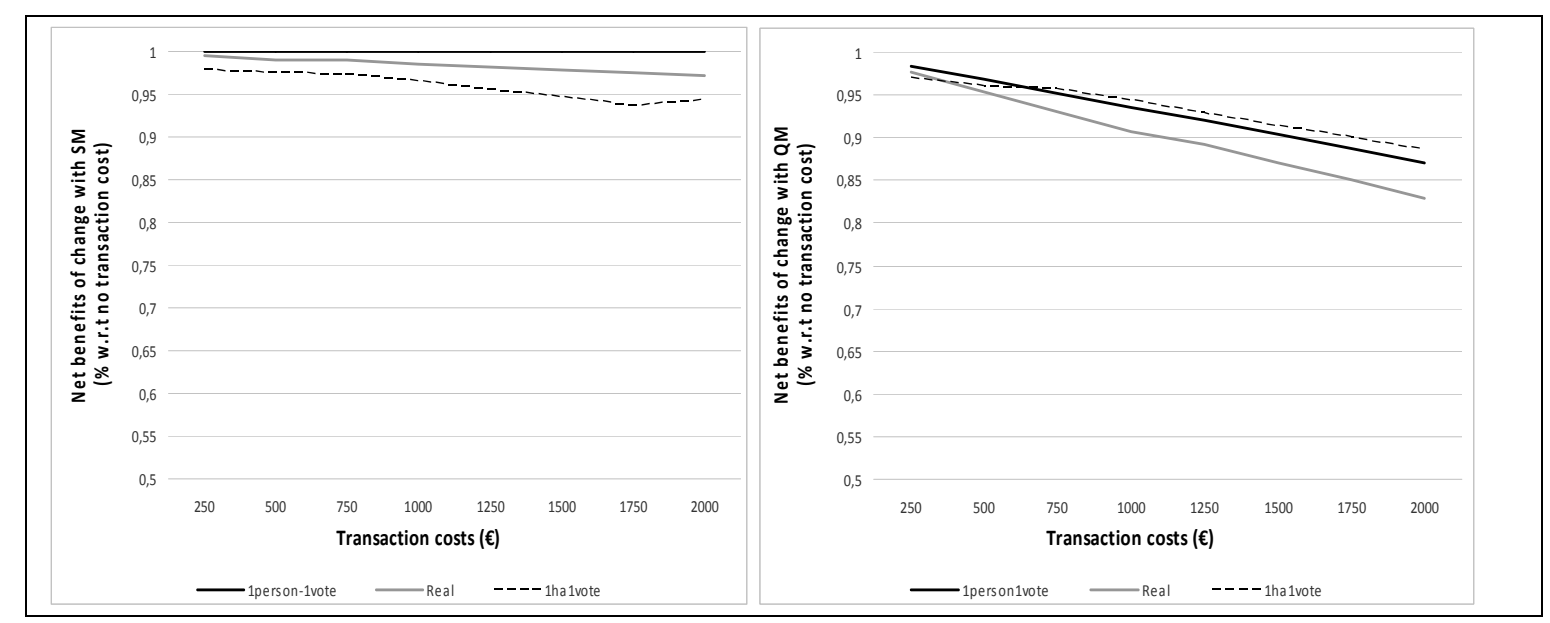

Fig. 8. Gains (\%) of the adoption of the sequential rule under different transaction cost scenarios. a) Simple majority, b) Qualified majority

Fig. 8 a) shows the influence of different voting methods under the simple majority rule on the total net benefits as a function of transaction costs. With "1person-1vote" the total net benefits are not affected by transaction costs since the optimal farmers' decision with simple majority is always the sequential rule. Results reveal that the net benefits decrease with "Real" and "1ha-1vote" voting methods. With respect to the cases of no transaction costs, the gains decrease to $97.1 \%$ for the "Real" voting method and to $94.3 \%$ for "1ha-1vote" method.

Fig. 8 b) is like Fig. 8 a) however for the case of a qualified majority. In this situation, the transaction costs reduce total gains for all voting methods. The gains in this case decrease to $87.1 \%$ with "1person-1vote" method, to $82.8 \%$ with "Real" method and to $88.6 \%$ with "1ha-1vote". The results show in general that the introduction of increasing transaction costs even in the case of severe scarcity does not eliminate the private gains of change.

\subsection{Effects of climatic change on efficiency and implementation possibilities}

To evaluate the robustness of our results with respect to changes of the context we analyze the allocative efficiency of the social rules in the presence of climate change. According to existing climate change scenarios for Spain, temperatures will increase, particularly in Southern Spain, and water resources will be severely affected, exacerbating droughts. The set of projections by Estrela et al. (2012) considers two different scenarios. For the Ebro River basin, where the study area is located, the 
projections for a moderate climate change scenario (B2) ${ }^{4}$ indicate that available water will decrease by 11 and 14\% over the time horizons 2041-2070 (medium term) and 2071-2100 (long term) respectively. Forecasts in the more pessimistic scenario, A2, estimate a reduction of water resources by 14 and $28 \%$ in the medium term and long term respectively. We use these two scenarios in order to analyze the effects of climate change on the efficiency and the probability of acceptance.

The similarity of the results of the long term B2 and the medium term A2 scenario, and the little differentiability between results of medium term B2 and long term B2 suggests to concentrate on the medium and long term results of A2 (14\% and 28\%). Table 5 illustrates that the frequency of droughts will increase by 50\% (from 2 to 3 every 15-year period) in the medium term and by $200 \%$ (from 2 to 6) by the end of the XXI century. As a consequence, climate change increases the number of periods where the sequential rule should be adopted. The discounted net benefits of the WUA for all water allocation rules will decrease and the sequential rule continues to be superior to the other rules.

Table 5. Discounted aggregate net benefits over 15 years when climate change is considered

\begin{tabular}{cclcc}
\hline $\begin{array}{c}\text { Projections with } \\
\text { climate change }\end{array}$ & $\begin{array}{c}\text { Frequency of } \\
\text { droughts }\end{array}$ & Allocation rule & $\begin{array}{c}\text { Discounted net } \\
\text { benefits } \\
\text { (thousand } € \text { ) }\end{array}$ & $\begin{array}{c}\text { Efficiency } \\
\text { losses (\%) }\end{array}$ \\
\hline \multirow{2}{*}{$\begin{array}{c}\text { Medium term } \\
(14 \%)\end{array}$} & Every 5 years & Proportional rule & 20694 & 8.72 \\
& & Uniform rule & 22350 & 1.41 \\
& & Sequential rule & 22573 & 0.43 \\
& & Market & 22670 & - \\
\hline \multirow{2}{*}{ Long term } & Every 2.5 years & Proportional rule & 20553 & 7.07 \\
& & Sniform rule & 22118 & 1.24 \\
& & Sequential rule & 22397 & 0.65 \\
\hline
\end{tabular}

Despite the superiority of the sequential rule, one can observe in Table 6 that the status-quo often prevails if side payments are not implemented, especially if a qualified majority is required for its approval. Therefore, side payments are necessary to obtain a sufficient number of votes. The maximal payments can rise in the medium and long

\footnotetext{
${ }^{4}$ The emission scenarios (B2 and A2) are part of the set of scenarios of emission of greenhouse gases used in Fourth Assessment Report of the Intergovernmental Panel on Climate Change (IPCC, 2007).
} 
term up to $11.82 \%$ and $10.53 \%$ of the total gains respectively. These magnitudes confirm the previously obtained result that even in case of severe droughts a small part of the gains is already sufficient to compensate the losers.

Table 6. Results of the voting process when climate change is considered

\begin{tabular}{|c|c|c|c|c|c|}
\hline \multirow[t]{2}{*}{$\begin{array}{l}\text { Projections } \\
\text { with } \\
\text { climate } \\
\text { change }\end{array}$} & \multirow[t]{2}{*}{$\begin{array}{c}\text { Ponderation } \\
\text { of votes }\end{array}$} & \multicolumn{2}{|c|}{$\begin{array}{c}\text { \# of years the sequential } \\
\text { rule will be } \\
\text { implemented } \\
\text { (without side payments) }\end{array}$} & \multicolumn{2}{|c|}{$\begin{array}{c}\text { Maximum } \\
\text { payment } \\
\text { for change }(€) \\
\text { (\% over total } \\
\text { efficiency gains) }\end{array}$} \\
\hline & & SM $^{1}$ & QM & $\mathbf{S M}^{1}$ & $\mathbf{Q M}$ \\
\hline \multirow[t]{3}{*}{$\begin{array}{l}\text { Medium } \\
\text { term }\end{array}$} & $\begin{array}{l}\text { 1person -1 } \\
\text { vote }\end{array}$ & 3 & 1 & 0 & $\begin{array}{c}1771,74 \\
(1.36)\end{array}$ \\
\hline & real & 1 & 1 & $\begin{array}{l}120,91 \\
(0.09)\end{array}$ & $\begin{array}{c}4557,39 \\
(3.5)\end{array}$ \\
\hline & 1ha - 1 vote & 1 & 1 & $\begin{array}{c}8401,5 \\
(6.45)\end{array}$ & $\begin{array}{c}15402,64 \\
(10.53)\end{array}$ \\
\hline \multirow[t]{3}{*}{ Long term } & $\begin{array}{l}\text { 1person -1 } \\
\text { vote }\end{array}$ & 6 & 3 & 0 & $\begin{array}{l}1820,3 \\
(1.21)\end{array}$ \\
\hline & real & 4 & 3 & $\begin{array}{l}116,21 \\
(0.08)\end{array}$ & $\begin{array}{c}4671,92 \\
(3.10)\end{array}$ \\
\hline & 1 ha - 1 vote & 3 & 2 & $\begin{array}{c}8480,1 \\
(5.62)\end{array}$ & $\begin{array}{c}15895,22 \\
(10.53)\end{array}$ \\
\hline
\end{tabular}

\section{Conclusions}

Water scarcity and droughts are one of the major environmental problems in Southern Europe and is likely to affect many river basins. Moreover, the situation is expected to aggravate in the near future due to climate change. Thus, policy makers are confronted with the challenge to design policies that balance water demand and supply. Water markets are often seen as an efficient instrument to this end. However, functioning markets can frequently not be established due to legal, physical or social barriers. As an alternative to markets, the economic literature proposed water allocation rules. The application of these rules, however, may be impaired by the lack of acceptance and implementation problems.

For the case of an agricultural water user association, this paper compared the allocative efficiency of the new allocation rules with the current water allocation rule and the market outcome. The results show that the sequential rule is superior to the uniform rule and both are superior to the current allocation rule. Their efficiency losses 
are relatively small compared to the market outcome. This result holds even more in the case of more frequent and severe droughts (climate change). Albeit the superiority of the new rules the water user association might not adopt them since the number of losers might be greater than the number of gainers. Depending on the assignment of votes per person and the type of majority (simple or qualified) the new allocation rules have the chance to be approved in the general assembly of the water users association. Our empirical study of the Almudevar water user association located in the Ebro river basin shows that the distribution of gains and losses among the farmers often impedes the approval of the new rule, mostly independent of the assignment of votes per person and the type of majority rule. However, side payments may tip the balance in favor of the new allocation rules. The calculations show that only a very small part of the gains is needed to compensate the losses of the farmers whose votes are necessary for the approval of the new allocation rule. Taking transaction costs into account present a nearly negligible obstacle since even high transaction costs are of minor magnitude compared to the overall gains of the new allocation rules. Overall, the study shows that the implementation of new allocation rules would help to balance supply and demand in an efficient manner in particular with climate change taken place in the near future.

To our best knowledge, this is first empirical application of the new allocation rule and more empirical studies are necessary to confirm our results. Another interesting option for future research would be the realization of a pilot study where a water user association, or at least some farmers of a water user association, examines the effect of the new allocation rules in practice.

\section{Acknowledgements}

We would like to thank Daniel Isidoro and María Teresa Jiménez-Aguirre from the Soils and Irrigation Department of Agrifood Research and Technology Centre of Aragon (CITA) for the provision of all data used in this study. This research has benefited from the financial support of the Generalitat de Catalunya (contract 2014SGR-1360), XREPP (Xarxa de Referència d'R+D+I en Economia i Polítiques Públiques), and of the Ministerio de Economía y Competitividad (contract ECO201345861-R) and of the Ministerio de Economía, Industria y Competitividad (ECO201675927-R). 


\section{Appendix}

Table A.1. Water allocation following the uniform rule

(It is assumed that all farmers have 1 ha and quantities are given in $\mathrm{m}^{3} / \mathrm{ha}$.)

\begin{tabular}{lccccc} 
& \multicolumn{4}{c}{ Farmers } & Remaining \\
\cline { 2 - 5 } Allocation & $\mathbf{1}$ & $\mathbf{2}$ & $\mathbf{3}$ & $\mathbf{4}$ & water \\
\hline Ideal share & 2385 & 7914 & 4682 & 3313 & 13008 \\
Initial guaranteed portion & 3252 & 3252 & 3252 & 3252 & \\
Water assigned 1st round & 2385 & & & & 10623 \\
Guaranteed portion & & 3541 & 3541 & 3541 & \\
Water assigned 2nd round & & & & 3313 & 7310 \\
Guaranteed portion & & 3655 & 3655 & & \\
Water assigned 3rd round & & 3655 & 3655 & & \\
\hline Final allocations & 2385 & 3655 & 3655 & 3313 & 0 \\
\hline
\end{tabular}

Table A.2. Water allocation following the sequential rule

(It is assumed that all farmers have 1 ha and quantities are given in $\mathrm{m}^{3} / \mathrm{ha}$ )

\begin{tabular}{lccccc}
\hline & \multicolumn{4}{c}{ Farmers } & Remaining \\
\cline { 2 - 5 } Allocation & $\mathbf{1}$ & $\mathbf{2}$ & $\mathbf{3}$ & $\mathbf{4}$ & water \\
\hline Ideal share & 2385 & 7914 & 4682 & 3313 & 13008 \\
Initial guaranteed portion & $3902^{1}$ & 3252 & 4553 & 1301 & \\
Water assigned 1st round & 2385 & & & & 10623 \\
Guaranteed portion & & 3794 & 5311 & 1518 & \\
Water assigned 2nd round & & & 4682 & & 5941 \\
Guaranteed portion & & 4243 & & 1698 & \\
Water assigned 3rd round & & 4243 & & 1698 & \\
\hline Final allocations & 2385 & 4243 & 4682 & 1698 & 13008 \\
\hline
\end{tabular}

${ }^{1}$ Water is initially assigned proportional to each farmer's maximum benefits per hectare 


\section{References}

Albiac, J., Martínez Y., y Xabadia, A. (2007). “El desafío de la gestión de los recursos hídricos”. Papeles de Economía Española, 113: 95-111.

Barberà, S., Jackson, M., Neme, A. (1997). Strategy-proof allotment rules. Games and Economic Behavior 18: 1-21.

Barberà, S., editor. (2005). Strategy Proofness. Amsterdam: Elsevier Science.

Barros R., Isidoro D., and Aragüés R. (2011). Long-term water balances in La Violada Irrigation District (Spain): II. Analysis of irrigation performance. Agricultural Water Management, 98: 1569-1576.

Bjornlund, H. (2003). "Farmer participation in markets for temporary and permanent water in southeastern Australia”. Agricultural Water Management 63: 57-76.

Burkhart, M. and Lee, S. (2008) One Share - One Vote: The Theory, Review of Finance, 12: $1-49$.

Calatrava, J., and Garrido, A. (2005). "Modelling spot water markets under uncertain water supply". European Review of Agricultural Economics, 32: 119-142.

Carey, J., Sunding, D., and Zilberman, D. (2002). "Transaction costs and trading behavior in an immature water market". Environmental and Development Economics, 7: 733-750.

Dekel, E. and Wolinsky, A. (2012) Buying Shares and/or Votes for Corporate Control, Review of Economic Studies 79: 196-226.

Easter W.K., and Hearne, R. (1995) "Water markets and decentralized water resources management: international problems and opportunities”. Water Resource Bulletin, 31: 9-20.

Easter, W., Rosegrant, M., and Dinar, A. (1998). Market for Water: Potential and Performance. Kluwer Academic Publisher, Boston MA.

Estrela T., Pérez-Martin M.A. and Vargas E. (2012). Impacts of climate change on water resources in Spain, Hydrological Sciences Journal, 57: 1154-1167, DOI: 10.1080/02626667.2012.702213

European Commission (2000). Water Framework Directive. 2000/60/EC European Parlament and Council, http://eur-lex.europa.eu/legalcontent/EN/TXT/PDF/?uri=CELEX:32000L0060\&rid=1, accessed 31.3.2017.

European Commission (2010) Water Scarcity and Drought in the European Union, Factsheet. http://ec.europa.eu/environment/pubs/pdf/factsheets/water_scarcity.pdf 
European Commission (2015). EU agriculture and climate change. European Climate Adaptation Platform. Accessible at: http://climate-adapt.eea.europa.eu/euadaptation-policy/sector-policies/agriculture

Feldman, A., and Serrano, R., (2006), Welfare Economics and Social Choice Theory (2. ed.) Springer, New York.

Goetz, R., Martínez, Y., and Rodrigo, J. (2005). "Eficiencia de las reglas de asignación de agua en el regadío: asignación a través de mercados, de la regla proporcional y de la regla uniforme. " Economía Agraria y Recursos Naturales, 9: 115-138.

Goetz, R., Martínez, Y. and Rodrigo, J. (2008). "Water allocation by social choice rules: The case of sequential rules". Ecological Economics, 65: 304-314.

Grossman, S. J. and Hart, O.D. (1980) Takeover Bids, the Free-Rider Problem, and the Theory of the Corporation. The Bell Journal of Economics, 11: 42-64.

Grossman, S. J. and Hart, O.D. (1988). One Share-One Vote and the market for Corporate Control. Journal of Financial Economics, 20: 175-202.

Harris, M. and Raviv, A. (1988). Corporate Governance: Voting Rights and Majority Rules, Journal of Financial Economics, 20: 203-235.

Howe, C., Schurmeier, D. and Shaw Jr., W. (1986). Innovative approaches to water allocation: the potential for water markets, Water Resources Research, 22: 439445.

INE (2016). Estadística sobre suministro y saneamiento del agua. Instituto Nacional de Estadística, Madrid.

Jiménez-Aguirre, M.T. and Isidoro, D. (2012). Efectos de la modernización de la Comunidad de Regantes de Almudévar (Huesca) sobre el cultivo del maíz. Tierras, 3: 102-110.

Lee, T.R., and Jouravlev, A.S. (1998). Los precios, la propiedad y los mercados en la asignación del agua. CEPAL (Naciones Unidas), Santiago de Chile.

MAPAMA (2016). Plan Nacional de Adaptación al Cambio Climático. Oficina española de cambio climático. Accessible at: http://www.mapama.gob.es/es/cambio-climatico/temas/impactos-vulnerabilidad-yadaptacion/pna_v3_tcm7-12445_tcm7-197092.pdf

Mendenhall, W., Wackerly, D. and Scheaffer, R. (1990). Mathematical Statistics with Applications, 4 edn, PWS-Kent, Boston. 
Mitchell G., Griggs R., Benson V. and Williams J. (1998): “The EPIC model: environmetal policy integrated climate”, Texas Agricultural Experiment Station. Temple.

OECD (2015). OECD Principles on Water Governance. Directorate for Public Governance and Territorial Development. Accesible at: https://www.oecd.org/gov/regional-policy/OECD-Principles-on-Water-

Governance-brochure.pdf

Serrano, R. (2004), The Theory of Implementation of Social Choice Rules, SIAM Review 46: 377-414.

Sprumont, Y., (1991). The division problem with single peaked preferences: a characterization of the uniform allocation rules, Econometrica 59: 509-519.

Torres, M. (1983). Balance hidrosalino de un polígono de riego en los Llanos de La Violada (Huesca). Tesis de Master del Instituto Agronómico Mediterráneo de Zaragoza (CIHEAM-IAMZ), Zaragoza, 273 p.

White, K.J. (2002): SHAZAM - For Windows, Version 9.0.

Wolfram Research, Inc. (2015) Mathematica, Versión 10.3, Champaign, IL. 